\title{
Determination of riboflavin by enhancing the chemiluminescence intensity of peroxomonosulfate-cobalt(II) system
}

\author{
Min Wang ${ }^{a}$, Lixia Zhao ${ }^{b}$, Meilin Liu ${ }^{b}$, Jin-Ming Lin ${ }^{\mathrm{a}, \mathrm{b}, *}$ \\ a The Key Laboratory of Bioorganic Phosphorus Chemistry \& Chemical Biology, Department of Chemistry, \\ Tsinghua University, Beijing 100084, China \\ ${ }^{\mathrm{b}}$ State Key Laboratory of Environmental Chemistry and Ecotoxicology, Research Center for Eco-Environmental Sciences, \\ Chinese Academy of Sciences, P.O. Box 2871, Beijing 100085, China
}

Received 6 April 2006; received in revised form 31 May 2006; accepted 19 June 2006

\begin{abstract}
A weak chemiluminescent (CL) emission was observed in the decomposition of peroxomonosulfate $\left(\mathrm{HSO}_{5}{ }^{-}\right)$, which would be accelerated in the presence of trace amounts of cobalt (II). The mechanism was due to the production of singlet oxygen $\left({ }^{1} \mathrm{O}_{2}\right)$. Interestedly, riboflavin can enhance the $\mathrm{CL}$ and the CL intensity was strongly dependent on riboflavin concentration. Based on this phenomenon, a flow injection analysis (FIA) CL method was established for the determination of riboflavin. Additionally, the possible CL mechanism is proposed based on the kinetic curve of the CL reaction, CL spectra, UV-vis spectra and fluorescent spectra. The CL intensity was correlated linearly with concentration of riboflavin over the range of $1.0 \times 10^{-4}$ to $1.0 \times 10^{-8} \mathrm{~g} \mathrm{~mL}^{-1}$; the detection limit was $9.0 \times 10^{-9} \mathrm{~g} \mathrm{~mL}^{-1}(\mathrm{~S} / \mathrm{N}=3)$; the relative standard deviation was $1.4 \%$ for $9 \times 10^{-7} \mathrm{~g} \mathrm{~mL}^{-1}$ riboflavin $(n=11)$. Furthermore, this method was applied to the determination of riboflavin in real tablets and injections successfully.
\end{abstract}

(C) 2006 Elsevier B.V. All rights reserved.

Keywords: Chemiluminescence; Peroxomonosulfate; Riboflavin; Cobalt (II); Flow injection analysis (FIA)

\section{Introduction}

The riboflavin, which is also called as Vitamin $\mathrm{B}_{2}$, is a primary component of flavoenzymes in the human body, which serves as the essential redox-active coenzymes associated with flavoenzymes that catalyze a variety of biochemical reactions, involving carbohydrate, protein or fat metabolism. It is also one of the water-soluble B-group vitamins essential to general health. The deficiency of Vitamin $B_{2}$ would be associated with numerous diseases such as various kinds of catarrh and dermatitis. Generally, riboflavin appears mainly in the free state in biological tissues and is excreted through urine (more than $60 \%$ of a single oral dosage). Therefore, the analysis of riboflavin is very important. Routine methods for the determination of riboflavin were based on its natural fluorescence [1,2]. Additionally, riboflavin was also determined by chemically modified electrode $[3,4]$ depending upon its electrical activity. Certainly, IR [5] and spectrophotometry [6] were used for

\footnotetext{
* Corresponding author. Tel.: +86 1062841953 ; fax: +86 1062841953.

E-mail address: jmlin@mail.rcees.ac.cn (J.-M. Lin).
}

its determination in the relative literature. On the other hand, some analytical techniques such as HPLC $[7,8]$ and capillary electrophoresis $[9,10]$ coupling with UV-vis or fluorescence detection were applied to determine riboflavin in real samples, for instance riboflavin pharmaceutical tablets and food.

In recent years, chemiluminescent (CL) methods have been recognized as a valuable approach to selective, sensitive analyses. It was applied widely in various fields for its high sensitivity, simple instrumentation, widely linear dynamic range and good reproducibility. So far, some classic CL systems have been utilized for the determination of riboflavin, such as luminol [11-13] and acidic potassium permanganate [14]. However, the limitation to these methods is the lacking of selectivity, the complexity of procedure or the large consumption of analytical reagents.

Peroxomonosulfate $\left(\mathrm{HSO}_{5}{ }^{-}\right)$is a strong, not-well-known and highly reactive oxidant [15], which decomposes rapidly in the presence of trace amounts of transition-metal ions. It has been used to determine trace amounts of $\mathrm{Co}$ (II) by spectrophotometry [16]. In this work, we found a strong CL phenomenon when a trace amount of riboflavin was added to $\mathrm{HSO}_{5}{ }^{-} / \mathrm{Co}^{2+}$ mixed solution. Based on the strong enhancing effect of riboflavin on this CL system, a new, rapid, simple, 


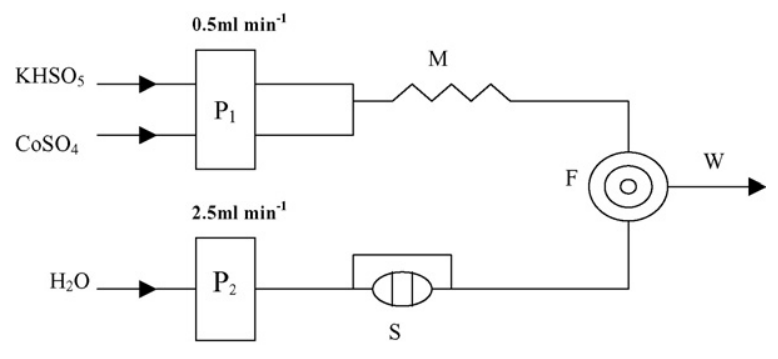

Fig. 1. Schematic diagram of the flow injection system for peroxomonosulfate chemiluminecscence. $\mathrm{P}_{1}$ and $\mathrm{P}_{2}$, peristaltic pump; $\mathrm{S}, 150 \mu \mathrm{L}$ sample injector; $\mathrm{M}$, mixing tubing $(1.0 \mathrm{~mm}$ i.d., $20 \mathrm{~cm}$ long); F, flow cell; $\mathrm{W}$, waste.

sensitive and inexpensive method is proposed to determinate riboflavin. Comparing with the other CL methods, it has more widely linear range and lower detection limit. Furthermore, the method has been used for the determination of riboflavin in real pharmaceutical preparations with satisfactory results.

\section{Experimental}

\subsection{Reagents}

All chemicals were of analytical grade and used as received. The solutions were prepared with high-purity water from a Milli-Q purification system $\left(18.3 \mathrm{M} \Omega \mathrm{cm}^{-1}\right.$, Millipore, Barnstead, CA, USA). Solutions of $\mathrm{KHSO}_{5}$ available in the form of a triple salt $\left(\mathrm{K}_{2} \mathrm{SO}_{4} \cdot \mathrm{KHSO}_{4} \cdot 2 \mathrm{KHSO}_{5}\right)$ as Oxone (Alfa, Ward Hill, USA) and cobalt (II) sulfate $\left(\mathrm{CoSO}_{4}\right)$ (Beijing Chemical Reagent Company, Beijing, China) were prepared daily. A $5.0 \times 10^{-5} \mathrm{~g} \mathrm{~mL}^{-1}$ riboflavin stock solution was prepared by dissolving $5.0 \mathrm{mg}$ of riboflavin (Kanto Chemical, Japan) in pure water and diluting to $100 \mathrm{~mL}$, then stored at $4{ }^{\circ} \mathrm{C}$ and protected from the light.

\subsection{Apparatus}

The schematic diagram of the flow system is shown in Fig. 1. Two peristaltic pumps (Baoding Lange Limited Company, Heibei, China) were used to deliver three flow-lines at the optimum flow rates. The solutions were introduced continuously into the flow cell by means of PTFE flow tubes $(0.8 \mathrm{~mm}$ i.d.). The flow cell placed close to the window of the photomultiplier tube (PMT). In addition, it also includes a CL detector (Lumiflow LF-800, NITI-ON, Funabashi, Japan) and a 150$\mu \mathrm{L}$ loop injector placed close to the luminometer. The peak height of the signals recorded was measured as CL intensity. UV-vis and fluorescence spectra of reaction products were measured with a spectrophotometer (Shimadzu UV-2401PC, Kyoto, Japan) and a fluorescence spectrometer (Hitachi F-2500, Japan), respectively. The batch method was carried out with the BPCL ultra-weak luminescence analyzer (Institute of Biophysics, Chinese Academy of Science, Beijing, China) coupling with a PC2000 computer. $\mathrm{O}_{2}$ contents before and after chemiluminescence reaction were carried out with a dissolved oxygen meter $\left(\mathrm{O}_{2}\right.$-sensing polarographic electrode) (WTW Oxi330i, Germany).

\subsection{Procedures}

The flow injection analysis (FIA) manifold is shown in Fig. 1. Before each measurement, the instruments were allowed to carry solutions for $10 \mathrm{~min}$ to achieve good mechanical and thermal stability. Riboflavin standard solution $(150 \mu \mathrm{L})$ or sample solution was injected into the carrier stream (water) and mixed with $0.02 \mathrm{~mol} \mathrm{~L}^{-1}$ potassium peroxomonosulfate solution and $0.01 \mathrm{~mol} \mathrm{~L}^{-1}$ cobalt (II) sulfate solution in the spiral flow CL cell. The CL intensity was considered as the blank intensity when $\mathrm{KHSO}_{5}$ and $\mathrm{CoSO}_{4}$ solution were mixed. A $20 \mathrm{~cm}$ mixing tubing was used to enhance the mixing of $\mathrm{KHSO}_{5}$ and $\mathrm{CoSO}_{4}$ solutions due to the $\mathrm{CL}$ signal exhibited a maximum at ca. $3 \mathrm{~min}$ after mixing of $\mathrm{KHSO}_{5}$ and $\mathrm{CoSO}_{4}$ [17]. The concentration of riboflavin was quantified via the peak height of the relative CL intensity, which was obtained by subtracting the blank CL intensity from that of the sample or riboflavin standard solution.

\subsection{Sample preparation}

Not less than 10 tablets were accurately weighed, then ground to fine powder. A tablet sample equivalent to approximately $5 \mathrm{mg}$ riboflavin was weighed accurately, then dissolved in pure water and diluted into $100 \mathrm{~mL}$. More than 10 injections were mixed. An injection sample which is equivalent to about $5 \mathrm{mg}$ of riboflavin is diluted into $100 \mathrm{~mL}$ with pure water. The tablet sample and the injection sample were filtered before measured and the clear filtrates were used for spectroscopic determination as reference method [6]. The samples were diluted with pure water before used so that the final analyte concentrations were matched with the working curve range. To avoid strong photolysis of riboflavin [18], all the sample solutions should be protected from blazing light during the experiment.

\section{Results and discussion}

\subsection{CL method}

A weak CL signal was yielded owing to decomposition of $\mathrm{HSO}_{5}{ }^{-}$without buffer solution [19], and $\mathrm{Co}^{2+}$ is a good catalyst for its decomposition has been known for a long time [17]. The CL profile in the batch method for the mixtures of $\mathrm{HSO}_{5}{ }^{-}, \mathrm{Co}^{2+}$ and riboflavin solution is shown in Fig. 2. On the basis of the curve, mixing of $\mathrm{HSO}_{5}{ }^{-}$solution with $\mathrm{Co}^{2+}$ solution gave evidence of CL emission, which will be the blank CL emission in CL flow system. A stronger and sharper CL signal appeared when the riboflavin solution was added to the $\mathrm{HSO}_{5}{ }^{-} / \mathrm{Co}^{2+}$ mixed solution. The $\mathrm{CL}$ reached maximum intensity at $2 \mathrm{~s}$ and decayed within $10 \mathrm{~s}$. This result means that the reaction of riboflavin with the reactive species is a fast process. Therefore, the present CL system can be developed as a FIA for the determination of riboflavin.

\subsection{Optimization of the reaction conditions}

To establish the optimal conditions for the flow injection analysis of riboflavin, the peak height of the relative CL intensity, 
Table 1

Analytical parameters for the determination of riboflavin

\begin{tabular}{lll}
\hline Range of application $\left(\mathrm{g} \mathrm{mL}^{-1}\right)$ & Equation of calibration line, $\Delta I=a C+b$ & Correlation coefficient $\left(R^{2}\right)$ \\
\hline $1.0 \times 10^{-8}$ to $1.0 \times 10^{-6}$ & $\Delta I=24.77 \times 10^{7} C+8.636(n=11)$ & 0.9981 \\
$1.0 \times 10^{-6}$ to $1.0 \times 10^{-5}$ & $\Delta I=58.98 \times 10^{6} C+363.44(n=5)$ & 0.9969 \\
$1.0 \times 10^{-5}$ to $1.0 \times 10^{-4}$ & $\Delta I=83.56 \times 10^{5} C+910.59(n=6)$ & 0.9917 \\
\hline
\end{tabular}

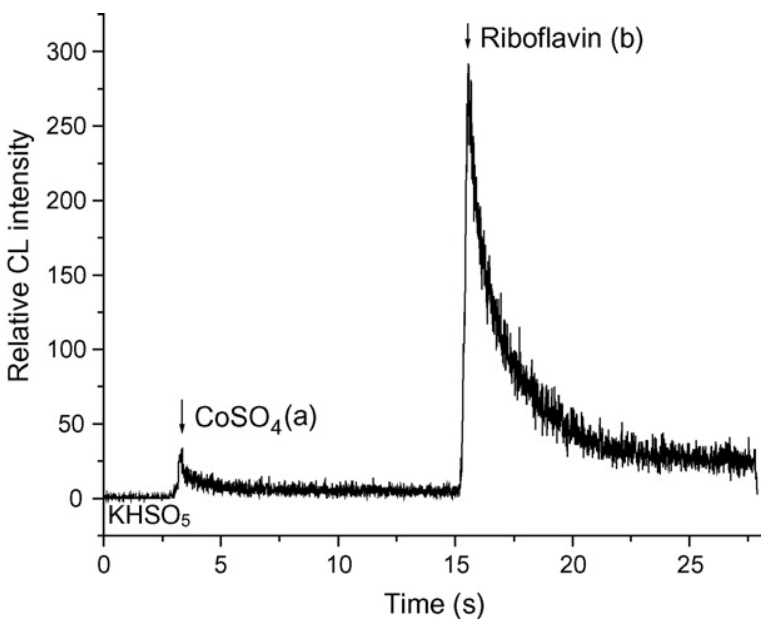

Fig. 2. Chemiluminescence kinetic curve of $\mathrm{KHSO}_{5}-\mathrm{CoSO}_{4}$-riboflavin system: (a) injection $\mathrm{CoSO}_{4}$ solution into $\mathrm{KHSO}_{5}$ solution and (b) injection riboflavin solution into $\mathrm{KHSO}_{5} / \mathrm{CoSO}_{4}$ mixed solution. The concentrations of $\mathrm{KHSO}_{5}$, $\mathrm{CoSO}_{4}$ and riboflavin are $0.02 \mathrm{~mol} \mathrm{~L}^{-1}, 0.01 \mathrm{~mol} \mathrm{~L}^{-1}$ and $5.0 \times 10^{-7} \mathrm{~g} \mathrm{~mL}^{-1}$, respectively. The volume of each reagent solution is $100 \mu \mathrm{L}$.

which was obtained by subtracting the blank CL intensity from that of the sample or riboflavin standard solution, was looked as a function of the concentrations of $\mathrm{KHSO}_{5}$ and $\mathrm{CoSO}_{4}$.

The concentration of peroxomonosulfate had a very important effect on the relative CL intensity for the determination of riboflavin. The initial testing showed that the ratio of the enhancing CL signal of riboflavin to the blank peroxomonosulfate $\mathrm{CL}$ signal was greatly dependent upon the peroxomonosulfate concentration. The effect of $\mathrm{HSO}_{5}{ }^{-}$concentration on the $\mathrm{CL}$ signal was investigated in the $0.006-0.16 \mathrm{~mol} \mathrm{~L}^{-1}$ range. The results showed that a concentration of $0.02 \mathrm{~mol} \mathrm{~L}^{-1} \mathrm{HSO}_{5}{ }^{-}$was operated as one of FIA CL optimum conditions.

The CL intensity was strongly dependent on the concentration of $\mathrm{CoSO}_{4}$ because $\mathrm{Co}^{2+}$ affected the decomposition of $\mathrm{HSO}_{5}{ }^{-}$. The effect of $\mathrm{CoSO}_{4}$ concentration on the CL intensity was also examined. The $\mathrm{CL}$ intensity was found to increase with increasing the concentration of $\mathrm{CoSO}_{4}$ in the range of $0.002-0.01 \mathrm{~mol} \mathrm{~L}^{-1}$, because the catalytic decomposition of $\mathrm{HSO}_{5}{ }^{-}$generated more ${ }^{1} \mathrm{O}_{2}$ with increasing the concentration of $\mathrm{Co}^{2+}$, which could transfer energy to riboflavin. Further increase in $\mathrm{CoSO}_{4}$ concentration caused a gradually decrease in emission intensity. The reason was probably that too much $\mathrm{HSO}_{5}{ }^{-}$was consumed during the conversion of plentiful $\mathrm{Co}^{2+}$ and $\mathrm{Co}^{3+}$, which limited the yield of ${ }^{1} \mathrm{O}_{2}$. This cause can be deduced from Eqs. (1)-(6). Based on these, a concentration of $0.01 \mathrm{~mol} \mathrm{~L}^{-1}$ $\mathrm{CoSO}_{4}$ was chosen in further experiments.

The flow rate is an important factor in flow-injection analysis which influences not only analytical efficiency but also the sen- sitivity of the system. The effect of the flow rate on CL intensity was examined in the range of $0.5-3.5 \mathrm{~mL} \mathrm{~min}^{-1}$. The results showed that the CL signal increased with the increasing flow rate of carrier stream in the range $0.5-2.5 \mathrm{~mL} \mathrm{~min}^{-1}$, probably because this $C L$ reaction is a rapid reaction. Above the flow rate $2.5 \mathrm{~mL} \mathrm{~min}^{-1}$, however, the CL intensity declined, probably because higher flow rates with shorter contact time result in insufficient CL reaction. So, a flow rate of $2.5 \mathrm{~mL} \mathrm{~min}^{-1}$ for carrier stream was selected as optimum. On the other hand, the $\mathrm{CL}$ intensity declined with the declining flow rates of $\mathrm{KHSO}_{5}$ and $\mathrm{CoSO}_{4}$ in the range $0.5-3.5 \mathrm{~mL} \mathrm{~min}^{-1}$. Thus, the flow rate of $0.5 \mathrm{~mL} \mathrm{~min}^{-1}$ was selected as an appropriate condition considering both good analytical precision and lower solution consumption.

\subsection{Analytical performance}

Under the optimum experimental conditions employed in present study, the calibration graphs of relative CL intensity versus riboflavin concentration over the range $1.0 \times 10^{-4}$ to $1.0 \times 10^{-8} \mathrm{~g} \mathrm{~mL}^{-1}$ were obtained. The results showed in Table 1. The determination limit was $9.0 \times 10^{-9} \mathrm{~g} \mathrm{~mL}^{-1}$ $(\mathrm{S} / \mathrm{N}=3)$ of riboflavin in the $\mathrm{HSO}_{5}{ }^{-} / \mathrm{Co}^{2+} \mathrm{CL}$ system. The relative standard deviation was found to be $1.4 \%$ by 11 replicate determinations of $9 \times 10^{-7} \mathrm{~g} \mathrm{~mL}^{-1}$ riboflavin.

\subsection{Interference studies}

The influence of foreign species was investigated by analyzing a standard solution of $5 \times 10^{-7} \mathrm{~g} \mathrm{~mL}^{-1}$ riboflavin to which increasing amounts of interfering species were added. A substance was considered no interference if the variation of the CL intensity was $\pm 5 \%$. The results were listed in Table 2 . Common excipients such as starch and sugar in tablets or injections do not interfere in the determination. Therefore, the flow method proposed has adequate selectivity for the determination of riboflavin.

Table 2

Tolerable concentration ratios with respect to riboflavin for some interfering species

\begin{aligned} & \hline Tolerance concentration ratio Species \\ & \hline 1000 $\mathrm{~K}^{+}, \mathrm{Zn}^{2+}, \mathrm{Cu}^{2+}, \mathrm{Al}^{3+}, \mathrm{Mg}^{2+}, \mathrm{Ni}^{2+} \\ & 500 \mathrm{Fe}^{2+}, \mathrm{Cr}^{3+} \\ & 100$ Nicotinic acid, dextrin \\ & 50 Sucrose, starch, citric acid \\ & 20 Maltose \\ & 10 Glucose, $\mathrm{Fe}^{3+} \\ & 2$ Phenylformic acid \\ & \hline\end{aligned}




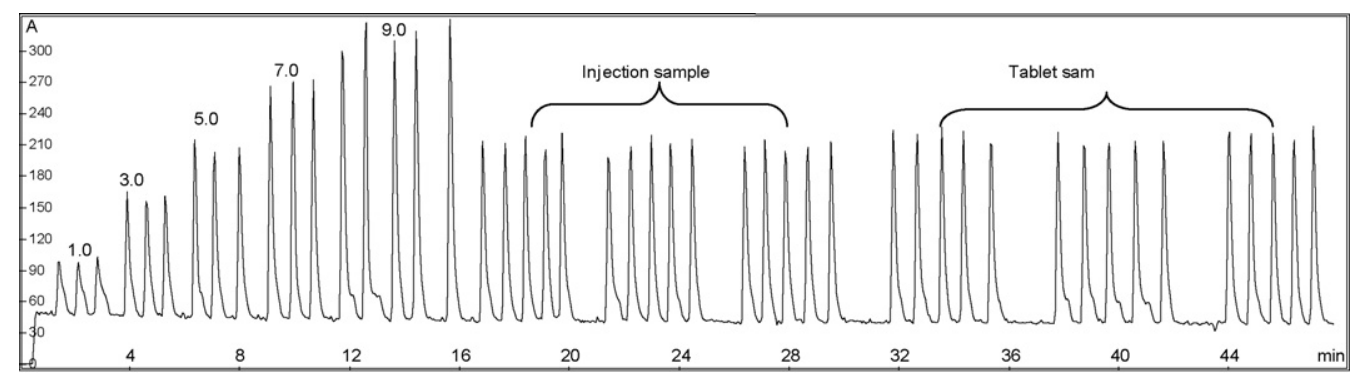

Fig. 3. Typical recorder response for the determination of standard riboflavin solutions $\left(10^{-7} \mathrm{~g} \mathrm{~mL}^{-1}\right)$ and the determination of riboflavin samples in Vitamin $\mathrm{B}_{2}$ tablet and injection by standard additions method.

Table 3

Determination of riboflavin in Vitamin $\mathrm{B}_{2}$ tablet samples and injection samples

\begin{tabular}{|c|c|c|c|c|c|}
\hline Sample & Measured $\left(\mathrm{g} \mathrm{mL}^{-1}\right)$ & R.S.D. (\%) & Added $\left(\mathrm{g} \mathrm{mL}^{-1}\right)$ & Founded $\left(\mathrm{g} \mathrm{mL}^{-1}\right)$ & Recovery (\%) \\
\hline \multicolumn{6}{|c|}{ Tablet sample } \\
\hline 1 & $1.12 \times 10^{-7}$ & 1.8 & $1.0 \times 10^{-7}$ & $2.14 \times 10^{-7}$ & 102.0 \\
\hline 2 & $2.75 \times 10^{-7}$ & 1.1 & $2.5 \times 10^{-7}$ & $5.34 \times 10^{-7}$ & 103.6 \\
\hline 3 & $5.50 \times 10^{-7}$ & 2.2 & $5.0 \times 10^{-7}$ & $10.28 \times 10^{-7}$ & 95.6 \\
\hline \multicolumn{6}{|c|}{ Injection sample } \\
\hline 1 & $1.02 \times 10^{-7}$ & 2.6 & $1.0 \times 10^{-7}$ & $2.07 \times 10^{-7}$ & 105.0 \\
\hline 2 & $2.55 \times 10^{-7}$ & 1.0 & $2.5 \times 10^{-7}$ & $5.09 \times 10^{-7}$ & 101.6 \\
\hline 3 & $5.07 \times 10^{-7}$ & 1.0 & $5.0 \times 10^{-7}$ & $9.86 \times 10^{-7}$ & 95.8 \\
\hline
\end{tabular}

\subsection{Application}

In order to evaluate the applicability and reliability of the proposed methodology, it was applied to the determination of riboflavin in Vitamin $B_{2}$ tablets and Vitamin $B_{2}$ injections. Following procedure has been described in the section of sample preparation. The recoveries were checked by comparing the $\mathrm{CL}$ signals from the samples with those from standard riboflavin at the same concentration. The results are shown in Fig. 3 and Table 3. Furthermore, the results were compared with those obtained by the method described in the Pharmacopoeia [6], which accorded to those obtained by the standard method.

\subsection{Possible mechanism}

Many investigations [20-22] have discussed the decomposition mechanism of $\mathrm{HSO}_{5}{ }^{-}$and confirmed that the decomposition of $\mathrm{HSO}_{5}{ }^{-}$generated singlet oxygen $\left({ }^{1} \mathrm{O}_{2}\right)$, an excited state of molecular oxygen, which can be quenched by $\mathrm{NaN}_{3}$ [19]. In the present experiment, the CL intensity of riboflavin with $\mathrm{HSO}_{5}{ }^{-} / \mathrm{Co}^{2+}$ mixed solution was decreased in the presence of $\mathrm{NaN}_{3}$, and the CL emission decreased with an increase of $\mathrm{NaN}_{3}$ concentration. The results validated the existence of ${ }^{1} \mathrm{O}_{2}$. The other proof for the generation of ${ }^{1} \mathrm{O}_{2}$ was the change of the $\mathrm{O}_{2}$ content before and after chemiluminescence reaction with the dissolved oxygen meter $\left(\mathrm{O}_{2}\right.$-sensing polarographic electrode). As shown in Table 4, the concentration of dissolving oxygen obviously increased after $\mathrm{KHSO}_{5}$ solution and $\mathrm{CoSO}_{4}$ solution were mixed. This owes to the conversion of singlet oxygen into triple oxygen.

In order to identify the emitting species after added riboflavin solution, CL spectra was also measured. The CL spectrum of the reaction of the $\mathrm{HSO}_{5}{ }^{-}-\mathrm{Co}^{2+}$ and riboflavin is shown in Fig. 4. It can be seen that the CL maximum wavelength of riboflavin is located at ca. $525 \mathrm{~nm}$, which is similar to the fluorescence spectra of riboflavin reported in previous literature [23]. The CL emission may be a result of a radiative transition of electrons from the first singlet excited electronic state to the ground state of riboflavin. It also confirmed a fact that riboflavin enhances the $\mathrm{CL}$ emission by the energy transfer from ${ }^{1} \mathrm{O}_{2}$ to riboflavin.

Although the $\mathrm{CL}$ of the riboflavin induced by $\mathrm{Co}^{2+}$ catalyzed decomposition of $\mathrm{HSO}_{5}{ }^{-}$can be explained by the above mechanism, the color of the riboflavin solution changing to colorless from bright yellow after adding the $\mathrm{HSO}_{5}{ }^{-} / \mathrm{Co}^{2+}$ mixed solutions for $10 \mathrm{~min}$ is difficult to interpret. The fluorescent spectra of riboflavin with and without the addition of $\mathrm{HSO}_{5}{ }^{-} / \mathrm{Co}^{2+}$ mixed solution have been shown in curve 1 of Fig. 5, the maximum fluorescent wavelength of riboflavin is $525 \mathrm{~nm}$, which is in accordance with the CL spectrum of riboflavin. It means that riboflavin

Table 4

The concentration of dissolving oxygen of riboflavin before and after reacting with $\mathrm{KHSO}_{5} / \mathrm{CoSO}_{4}$ solution

\begin{tabular}{lll}
\hline Number & Solution & $\begin{array}{l}\text { Concentration of dissolving } \\
\text { oxygen }\left(\mathrm{mg} \mathrm{L}^{-1}\right)\end{array}$ \\
\hline 1 & $\mathrm{H}_{2} \mathrm{O}$ & 6.80 \\
2 & $\mathrm{HSO}_{5}{ }^{-}$ & 9.71 \\
3 & $\mathrm{HSO}_{5}{ }^{-}+\mathrm{CoSO}_{4}$ & 58.7 \\
4 & $\mathrm{Riboflavin}_{5}$ & 8.80 \\
5 & $\mathrm{HSO}_{5}{ }^{-}+\mathrm{CoSO}_{4}+$ riboflavin & 51.7 \\
\hline
\end{tabular}

The concentrations of $\mathrm{HSO}_{5}{ }^{-}, \mathrm{CoSO}_{4}$ and riboflavin were $0.02 \mathrm{~mol} \mathrm{~L}^{-1}$, $0.01 \mathrm{~mol} \mathrm{~L}^{-1}$ and $5.0 \times 10^{-7} \mathrm{~g} \mathrm{~mL}^{-1}$, respectively. The batch method was used. 


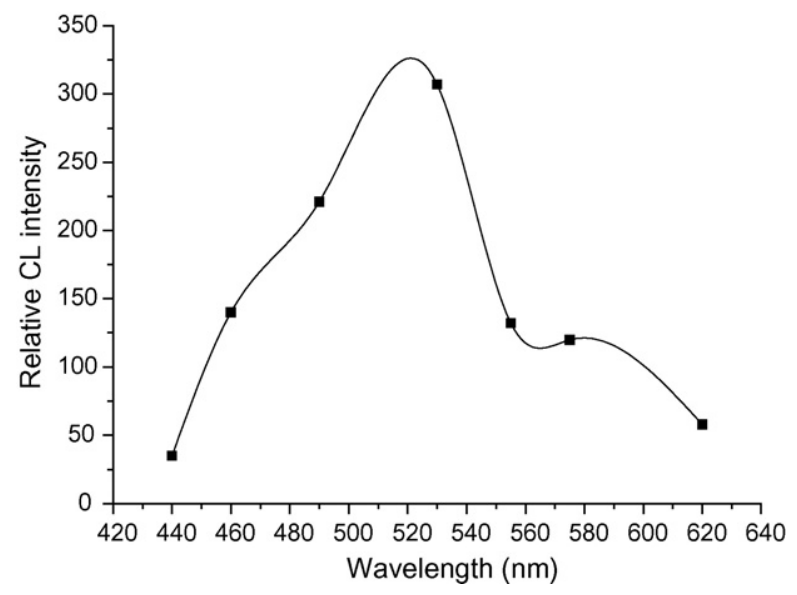

Fig. 4. CL spectrum of the $\mathrm{HSO}_{5}{ }^{-}-\mathrm{Co}^{2+} /$ riboflavin reaction. The concentrations of $\mathrm{HSO}_{5}{ }^{-}, \mathrm{CoSO}_{4}$ and riboflavin were $0.02 \mathrm{~mol} \mathrm{~L}^{-1}, 0.01 \mathrm{~mol} \mathrm{~L}^{-1}$ and $5.0 \times 10^{-7} \mathrm{~g} \mathrm{~mL}^{-1}$, respectively. The batch method was used. The volume of each reagent solution is $100 \mu \mathrm{L}$.

acts an energy acceptor and sensitizes the CL emission. Furthermore, the reaction of riboflavin with $\mathrm{HSO}_{5}{ }^{-} / \mathrm{Co}^{2+}$ mixed solution was also monitored by the fluorescent detection. As shown in Fig. 5 (curves 2-6), the fluorescent intensity decreased quickly after adding the $\mathrm{HSO}_{5}{ }^{-} / \mathrm{Co}^{2+}$ mixed solution into the riboflavin solution. The UV-vis spectra of riboflavin were also shown in Fig. 6. Similar to the fluorescence result, the absorptions were decreased or disappeared after the riboflavin reacted with the $\mathrm{HSO}_{5}{ }^{-} / \mathrm{Co}^{2+}$ mixed solution. Based on these results, it can be confirmed that the chemical structure of riboflavin was destroyed in the CL reaction. The reasonable explanation may be that $\mathrm{HSO}_{5}{ }^{-}$is decomposed by the catalysis of $\mathrm{Co}^{2+}$, and produce reactive species $\left(\mathrm{SO}_{4}{ }^{\bullet-}, \mathrm{SO}_{5}{ }^{\bullet-}\right.$, etc. $)$ [24], which are strong oxidants leading to the oxidization of riboflavin, and the process of oxidization is a slow reaction comparing with the $\mathrm{CL}$ emission. In a conclusion, the formation of CL emission may take place as the following reactions:

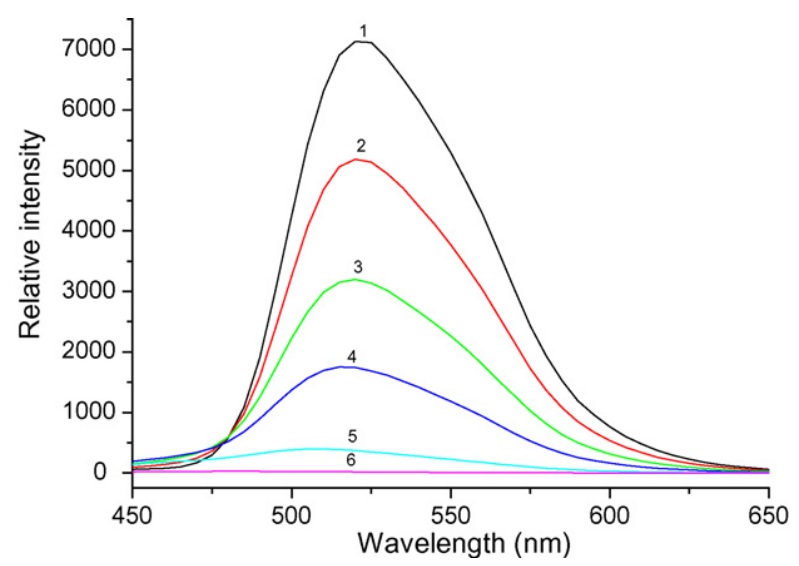

Fig. 5. Fluorescent spectra of riboflavin with and without the addition of $\mathrm{KHSO}_{5} / \mathrm{CoSO}_{4}$ mixed solution. (1) $1.0 \times 10^{-6} \mathrm{~g} \mathrm{~mL}^{-1}$ riboflavin solution; (2) $3.0 \mathrm{~mL}$ of $1.0 \times 10^{-6} \mathrm{~g} \mathrm{~mL}^{-1}$ riboflavin solution $+50 \mu \mathrm{L}$ of $0.01 \mathrm{~mol} \mathrm{~L}^{-1}$ $\mathrm{CoSO}_{4}$ and $50 \mu \mathrm{L}$ of $0.02 \mathrm{~mol} \mathrm{~L}^{-1} \mathrm{KHSO}_{5}$. The mixing time of the three reagents was $30 \mathrm{~s}$ : (3) (2) with 1-min mixing time; (4) (2) with 2-min mixing time; (5) (2) with 4-min mixing time; (6) (2) with 25-min mixing time.

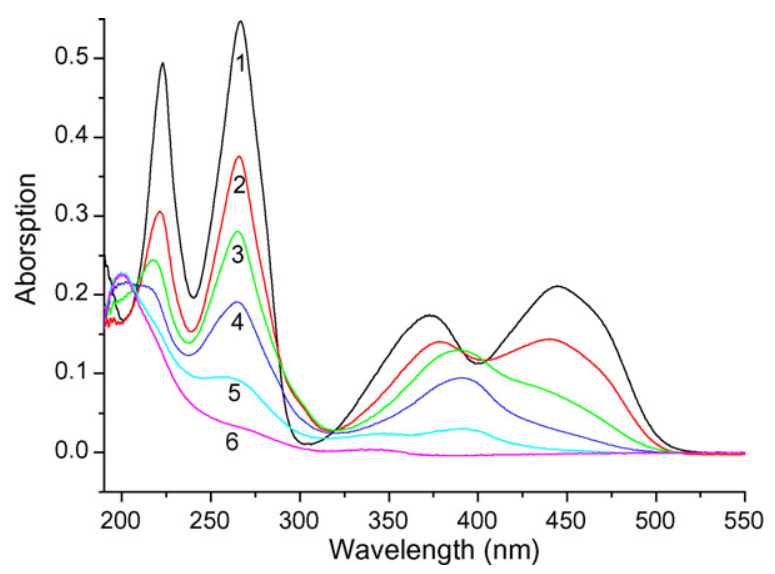

Fig. 6. UV-vis spectra of riboflavin before and after reacting with $\mathrm{KHSO}_{5} / \mathrm{CoSO}_{4}$ solution. Reference solution is water. (1) $5.0 \times 10^{-6} \mathrm{~g} \mathrm{~mL}^{-1}$ riboflavin solution; (2) $3.0 \mathrm{~mL}$ of $5.0 \times 10^{-6} \mathrm{~g} \mathrm{~mL}^{-1}$ riboflavin solution $+100 \mu \mathrm{L}$ of $0.01 \mathrm{~mol} \mathrm{~L}^{-1} \mathrm{CoSO}_{4}$ and $100 \mu \mathrm{L}$ of $0.02 \mathrm{~mol} \mathrm{~L}^{-1} \mathrm{KHSO}_{5}$. The mixing time of the three reagents was $50 \mathrm{~s}$ : (3) (2) with 2.5 -min mixing time; (4) (2) with 4-min mixing time; (5) (2) with 6-min mixing time; (6) (2) with 10-min mixing time.

$\mathrm{HSO}_{5}{ }^{-}+\mathrm{Co}^{2+} \longrightarrow \mathrm{SO}_{4}{ }^{-{ }^{-}}+\mathrm{Co}^{3+}+\mathrm{OH}^{-[24]}$

$\mathrm{Co}^{3+}+\mathrm{HSO}_{5}{ }^{-} \rightarrow \mathrm{Co}^{2+}+\mathrm{HSO}_{5} \quad[19]$

$\mathrm{HSO}_{5}{ }^{-}+\mathrm{SO}_{4}{ }^{\bullet-} \rightarrow \mathrm{SO}_{5}{ }^{\bullet-}+\mathrm{HSO}_{4}{ }^{-} \quad[20]$

$\mathrm{HSO}_{5}{ }^{-}+\mathrm{OH}^{\bullet} \rightarrow \mathrm{SO}_{5}{ }^{-}+\mathrm{H}_{2} \mathrm{O} \quad[21]$

$2 \mathrm{SO}_{5}{ }^{\bullet-}+\mathrm{H}_{2} \mathrm{O} \rightarrow 2 \mathrm{HSO}_{4}{ }^{-}+\frac{3}{2}^{1} \mathrm{O}_{2} \quad[22]$

${ }^{1} \mathrm{O}_{2}+$ riboflavin $\rightarrow$ riboflavin* $+\mathrm{O}_{2}$

Riboflavin* $\rightarrow$ riboflavin $+h v \quad(525 \mathrm{~nm})$

$\mathrm{SO}_{4}{ }^{\bullet-}+$ riboflavin $\rightarrow \mathrm{SO}_{4}{ }^{2-}+$ non-fluorescent product

\section{Conclusion}

In this work, we found a strong CL emission when a trace amount of riboflavin was added to $\mathrm{HSO}_{5}{ }^{-} / \mathrm{Co}^{2+}$ mixed solution. The enhancing of the $\mathrm{CL}$ emission by riboflavin due to the energy transfer from ${ }^{1} \mathrm{O}_{2}$ to riboflavin was confirmed. On the basis of these, a FIA CL method for the determination of riboflavin is proposed. The dynamic range and detection limits of the proposed method for the determination of riboflavin are better than many of the previously reported CL methods. This method has a good sensitivity, selectivity and precision and it is very simple, rapid and inexpensive. Furthermore, the method was satisfactorily applied to the determination of riboflavin in pharmaceutical product samples.

\section{Acknowledgements}

The authors gratefully acknowledge financial support of the National Natural Science Foundation of China (Nos. 20437020 
and 20575008) and the Program for Changjiang Scholars and Innovative Research Team in University (No. IRT0404).

\section{References}

[1] R. Gatti, M.G. Gioia, Anal. Chim. Acta 538 (2005) 135.

[2] E.J. Llorent-Martínez, J.F. García-Reyes, P. Ortega-Barrales, A. MolinaDíaz, Anal. Chim. Acta 555 (2006) 128.

[3] S. Cosnier, M. Fontecave, D. Limosin, V. Niviere, Anal. Chem. 69 (1997) 3095.

[4] J. Wang, D.B. Luo, P.A.M. Farias, J.S. Mahmoud, Anal. Chem. 57 (1985) 158.

[5] C. Wojciechowski, N. Dupuy, C.D. Ta, J.P. Huvenne, P. Legrand, Food Chem. 63 (1998) 133.

[6] The Pharmacopoeia Committee of PRC, Pharmacopoeia of People's Republic of China [M]. Part 2, 2005th ed., Chemical Industry Press, Beijing, 2005, p. 665.

[7] F. Valls, M.T. Sancho, M.A. Fernandez-Muino, M.A. Checa, J. Agric. Food Chem. 47 (1999) 1067.

[8] C. Andrés-Lacueva, F. Mattivi, D. Tonon, J. Chromatogr. A 823 (1998) 355.
[9] P. Britz-McKibbin, K. Otsuka, S. Terabe, Anal. Chem. 74 (2002) 3736.

[10] A.K. Su, Y.S. Chang, C.H. Lin, Talanta 64 (2004) 970.

[11] L. Wang, Z.H. Song, Acta Pharmacol. Sin. 37 (2002) 793.

[12] G.F. Zhang, H.Y. Chen, Anal. Lett. 33 (2000) 3285.

[13] A. Safavi, M.A. Karimi, M.R. Hormozi Nezhad, Luminescence 20 (2005) 170.

[14] L.Q. Li, Y.M. Zhou, X.J. Tao, M.L. Feng, J.R. Lu, Chin. J. Anal. Chem. 27 (1997) 1333.

[15] D.L. Ball, J.O. Edwards, J. Am. Chem. Soc. 78 (1956) 1125.

[16] M. Endo, M. Ishihara, T. Yotsuyanagi, Analyst 121 (1996) 391

[17] S. Tsukada, H. Miki, J.-M. Lin, T. Suzuki, M. Yamada, Anal. Chim. Acta 371 (1998) 163.

[18] I. Ahmad, Q. Fasihullah, F.H.M. Vaid, Photochem. Photobiol. 75 (2004) 13.

[19] J.-M. Lin, M. Yamada, Anal. Chem. 72 (2000) 1148.

[20] Z.M. Zhang, J.O. Edwards, Inorg. Chem. 31 (1992) 3514.

[21] R.C. Thompson, Inorg. Chem. 20 (1981) 3745.

[22] M.H. Mariano, Anal. Chem. 40 (1968) 1662.

[23] M. Zandomeneghi, L. Carbonaro, L. Calucci, C. Pinzino, L. Galleschi, S. Ghiringhelli, J. Agric. Food Chem. 51 (2003) 2888.

[24] P. Maruthamuthu, P. Neta, J. Phys. Chem. 81 (1977) 937. 